\title{
DIVERSIFICATION POTENTIAL IN REAL ESTATE PORTFOLIOS
}

Bertrand Candelon, Franz Fuerst, JeanBaptiste Hasse

\section{LIDAM Discussion Paper LFIN $2021 / 01$}




\section{LFIN}

Voie du Roman Pays 34, L1.03.01 B-1348 Louvain-la-Neuve

Tel (32 10) 474304

Email: lidam-library@uclouvain.be

https://uclouvain.be/en/research-institutes/lidam/Ifin/publications.html 


\title{
Diversification Potential in Real Estate Portfolios *
}

\author{
Bertrand Candelon $^{\mathrm{a}}$, Franz Fuerst ${ }^{\mathrm{b}}$, Jean-Baptiste Hasse ${ }^{\mathrm{b}, \mathrm{c}}$ \\ ${ }^{a}$ Université Catholique de Louvain, Louvain Finance, Belgium \\ ${ }^{b}$ University of Cambridge, United Kingdom \\ ${ }^{c}$ Aix-Marseille Univ., CNRS, EHESS, Centrale Marseille, AMSE, Marseille, France
}

\begin{abstract}
Real estate, despite its spatial fixity, is subject to considerable cross-border investment flows. However, it may be surmised that the diversification potential of international real estate investments dwindles if markets become increasingly interlinked. Building on a unique dataset of direct real estate markets covering 16 OECD countries over the period 1999-2018, we compare country-level and sector-level diversification potential. We apply a relative Sharpe ratio loss approach and develop a modified version of this measure, relying on the modified Value-at-Risk, which is robust to non-normality. Using a studentized circular blockbootstrap procedure, robust confidence intervals for both measures are built. This new diversification test provides investors and analysts with a valuable tool as it delivers both estimates and robust significance levels. The empirical findings broadly reveal that international diversification strategies outperform sectoral diversification of real estate assets.
\end{abstract}

Keywords: Portfolio diversification, Real estate markets.

JEL Classification: C23, F21, G11, R33

*The authors are grateful to David Ardia and Kris Boudt for useful comments and to Lucas Pouzoulet for research assistance. The authors thank the seminar participants at the internal seminar at the Louvain Finance-Université Catholique de Louvain and the 2019 ERES annual conference at ESSEC Business School. This research was conducted as part of the research program entitled "Financial and Extra-financial Risk Modeling" under the aegis of the Europlace Institute of Finance, a joint initiative with Insti7. Franz Fuerst wishes to thank the Cambridge University Land Society (CULS) for continuous support of his research. The usual disclaimer applies.

Email addresses: candelonb@gmail.com (Bertrand Candelon), ff274@cam.ac.uk (Franz Fuerst), jean-baptiste.hasse@univ-amu.fr (Jean-Baptiste Hasse) 


\section{Introduction}

Commercial real estate attracts considerable investments in both direct and indirect markets due to its purported features. Chief among these are a perception of low or inverse correlation with stock and bond markets, potential inflation hedging benefits and outperformance vis-a-vis most other asset classes. Global real estate investments have enjoyed significant growth rates in recent years from USD 8.9 trillion in 2018 to USD 9.6 trillion in 2019 (Teuben and Neshat, 2020). A common strategy of institutional investors is to employ a top-down asset allocation, deciding first on a set of specific countries and property types and then moving into more fine-grained analysis and allocation at the individual asset level. The a priori selection of countries and property types can either be driven by macroeconomic and real estate sector analysis or by practical considerations, for example the expertise of investors or managers in particular markets, geographical proximity and ease of access to the assets under management. By definition, the top-down approach excludes investment opportunities that fall outside of the pre-defined areas and sectors, some of which may potentially enhance the risk-adjusted returns of a portfolio but cannot be pursued. By contrast, a bottom-up strategy does not set stringent exclusionary criteria but is prone to lacking a distinct strategic vision and coherent asset allocation rules. In practice, very few investors follow a pure top-down or bottom-up approach but typically use a combination of the two approaches (Worzala and Newell, 1997).

Despite a well established and increasingly sophisticated body of literature on the diversification benefits of real estate, it is still not well understood if diversification is generally best achieved at a global scale by diversifying portfolios across (1) property types such office, retail, industrial, hotels etc or (2) geographic markets in different countries. The present study investigates this question in the context of the diversification loss for a large number of countries and sectors for a dataset of real estate returns covering 16 countries in the 1999 - 2018 period. The traditional measure of the diversification loss in a portfolio based on correlation has been widely criticized by Calvet et al. (2007). They introduce a relative 
Sharpe ratio loss $(R S R L)$ approach and we extend their work proposing a modified version of this measure taken into account the modified Value-at-Risk and which is robust to nonnormality $(m R S R L)$. Following Ledoit and Wolf (2008) and Ardia and Boudt (2015; 2018), we use a studentized circle block-bootstrap procedure to build robust confidence intervals for both measures. It turns out that that a diversification strategy along geographic markets generally outperforms property type diversification. Such a finding is of major importance for asset managers specialized in the real estate sector.

The remainder of this paper is organised as follows. After reviewing the state of research on measuring portfolio diversification, both in real estate and other asset classes, we outline our research strategy and methodology, notably the relative Sharpe ratio loss $(R S R L)$ approach and propose a modified version that is robust to non-normality. We then proceed with the empirical analysis using the dataset mentioned above and present results on the diversification potential of the two principal strategies. Finally, we draw conclusions and review the implications for global real estate investors.

\section{State of Research}

Since Markowitz's seminal work in 1952, measuring portfolio diversification has become of major interest for both scholars and practitioners. In line with the modern portfolio theory (MPT), correlation and cluster analysis have long been used to measure diversification potential. Other methods have been used as proxies for diversification, such as the Herfindahl - Hirschman Index. However, focusing only on the weighting scheme of portfolios enables accounting for asset risks, but not for overall risk at a portfolio level. Inversely, focusing only on asset returns correlation is quite limited because it does not provide information about asset reward-risk ratios. As argued by Statman and Scheid (2008), both weighted asset returns and their correlations are needed to compute overall portfolio risks and returns, and hence to measure diversification. 


\subsection{Measuring diversification}

Recent works have attempted to build diversification indices that reconcile these two different approaches. Rudin and Morgan (2006) proposed the Portfolio Diversification Index $(P D I)$ based on a principal component analysis (PCA). Describing the most diversified portfolio, Choueifaty and Cognard (2008) introduced the diversification ratio $(D R)$. The $D R$ is defined as the ratio of the portfolio's weighted average variance to its overall variance (see also Choueifaty et al. (2013)). While this diversification measure has been popular among practitioners, the $D R$ is based on correlations, which means that it only accounts for the first two moments of the return distribution. To overcome this drawback, Tasche (2006) introduced a diversification index based on the Value-at-Risk. Meucci (2009) proposed the effective number of bets $(E N B)$, a diversification index based on the relationship between information entropy and portfolio diversification. Indeed, the Shannon entropy refers to the uncertainty related to an entire statistical distribution; i.e., higher diversification induces lower uncertainty and entropy. Thus, the common advantage of both Tasche's (2006) and Meucci's (2009) respective indices is to take into account idiosyncratic risks of individual assets using more than the first two moments of the return distribution. Vermorken et al. (2012) introduced a new measure of diversification: the diversification delta $(D D)$. The objective of this new measure is to capture benefits from an entropy-based diversification proxy and to be interpreted as a classic correlation coefficient. Highlighting several drawbacks of the $D D$, Flores et al. (2017) proposed a revised measure of this index: the diversification delta star $\left(D D^{*}\right)$. Their purpose was to overcome the drawbacks of the original $D D$ while retaining its attractive properties, such as its ease of computation and interpretation. Specifically, they revised the original $D D$ to satisfy the risk measure criteria of Artzner et al. (1999): homogeneity and subadditivity. Last, they also built the $D D^{*}$ to be bounded between 0 and 1.

The recent literature offers a set of several competing diversification measures. Easy to compute and to interpret, they nevertheless suffer from several common drawbacks. First, 
these measures are built to quantify the diversification level of a given portfolio, but not to compare diversification levels of several portfolios. Additionally, most of these recent measures are constructed from practitioners' specifications, being weakly connected to economic background. Last but not least, none of these diversification measures considers building confidence intervals, and neither conduct hypothesis testing. Considering these weaknesses, we follow another strand of the literature that offers interesting perspectives about diversification measurement. While investigating the ability of households to invest in efficient portfolios, Calvet et al. (2007) introduced the relative Sharpe ratio loss $(R S R L)$ and the return loss $(R L)$. Their aim is to quantify the household investment mistakes by comparing households' portfolios and a benchmark portfolio. In a classic mean-variance framework, the authors derive the $R S R L$ and $R L$ from $C A P M$; these indicators measure the extent of financial loss from holding a subefficient portfolio. Broadly speaking, the $R S R L$ and $R L$ proxy the distance between a given portfolio and the nearest portfolio on the efficient frontier. This measure of underdiversification is also used in Calvet et al. (2009) and Tang et al. (2010). These latest authors computed the empirical distribution of the $R S R L$ and, from confidence intervals, infer the $R S R L$ significance. More recently, Roche et al. (2013), Von Gaudecker (2015) and Dimmock et al. (2018) used the $R S R L$.

\subsection{Diversification potential in real estate portfolios}

The diversification benefits that can be achieved by extending the geographical coverage of an investment portfolio to multiple countries have been recognised in previous studies following Markowitz' paradigm (Markowitz 1952, Solnik 1974). At the same time, many of these studies warn that sufficient diversification in a direct real estate portfolio is only achievable for very large institutional portfolios (Byrne and Lee, 2003). A possible solution to this problem are indirect real estate investments, notably Real Estate Investment Trusts (REITs) whose return profiles offer significant but not perfect correlation with direct real estate returns (Hoesli and Oikarinen, 2012). A common caveat is that REITs are generally found to be positively correlated with equity markets (Peterson and Hsieh, 1997; Hoesli 
and Serrano, 2010; Lizieri, 2013). Hence, it may be argued that REITs only offer a partial exposure to the real estate market whilst being a less than ideal diversifier away from stock markets.

Notwithstanding these limitations, REITs and other real estate investment vehicles ought to be able to benefit from their underlying geographic and property type asset base. However, the proposition that diversification strategies yield a net benefit for real estate companies is not universally accepted. Hartzell et al. (2014) report that geographically diversified REITs were valued lower than their more geographically focused counterparts but further analysis showed that this discount can be mitigated by the involvement of large institutional owners in the REIT who actively monitor the REIT investment strategy. Feng et al. (2019) add another criterion for diversification benefits to materialise. In their study of equity REITs from 2010-16, the authors find diversified REITs with a high degree of transparency exhibit higher values whereas more opaque REITs appear to fare better when they are less diversified.

Apart from diversification, investors also seek to achieve an inflation hedge through their direct and indirect real estate investments. Hoesli et al. (2008) empirically test the long-term relationship between real estate yields and inflation by studying the private and public real estate markets in the United Kingdom and the United States. They find that this negative relationship is stronger for the private market than for the public market. While overall real estate market returns are on average uncorrelated with inflation, there is considerable variation in this relationship across direct and indirect real estate investment vehicles. In an earlier study, Eichholtz et al. (1995) analyse data from the USA and UK to compare efficient frontier portfolios of different property types and regions. The authors find that diversification by property type is not always necessary to achieve full diversification benefits. For example, they show that a US-retail portfolio is nearly as diversified as a fully diversified portfolio. However, they find that the UK shows less regional variation in retail returns than the USA and therefore diversification by property type appears to be the superior strategy in that market. 
The hybrid nature of indirect real estate investments means that direct brick-and-mortar investments remain an attractive proposition to many diversification-seeking investors despite the identified problems with minimum lot size, indivisibility, illiquidity, high transaction costs, high idiosyncratic risk, opaque markets and high management costs. How successful the diversification strategy of a direct real estate portfolio will be, depends crucially on the investment horizon. Heaney and Sriananthakumar (2012), Lizieri (2013) and Sing and Tan (2013) show that the relationship between equity market returns and those of the direct real estate market is not stable over time. However, the authors emphasize that this relation remains weak. Regression coefficients are reversed during economic crises and/or remain insignificant for certain periods. Regarding the public real estate market, the empirical literature offers more empirical evidence. Many studies describe a change in the correlation pattern between real estate market returns and other asset classes during a market downturn. Goldstein and Nelling (1999), Chatrath et al. (2000), Clayton and MacKinnon (2001), and more recently Hoesli and Reka $(2013 ; 2015)$ show that there is an asymmetry in the correlation between REIT and equity market returns, suggesting considerable co-movement between real estate and equity markets during market downturns and financial crises. However, Chiang et al. (2004) and Simon and Ng (2009) take the opposite view and argue that the observed changes in co-movement during different phases of the market cycle are due to underlying risk factors and that extreme dependencies are lower for REITs than they are for the equity market.

Despite the long-term nature of many real estate investments, relatively few studies investigate the long-term relationship between the real estate market and other asset classes. MacKinnon and Al Zaman (2009) find that the real estate proportion in an optimal multiasset portfolio increases with the investment horizon and note that REITs are redundant if direct real estate can be incorporated into the portfolio. In a similar vein, Rehring (2012) highlights the crucial role of return predictability for the role of real estate in a multi-asset portfolio. 
More recently, Leone and Ravishankar (2018) investigated if sector-region diversification is still a viable strategy for improving portfolio-specific efficiency. Using Stochastic Frontier Analysis in a UK portfolio context, they report that empirically there is indeed scope for improving portfolio efficiency and lowering the variability of portfolio efficiency levels over time.

The consensus emerging from the extant literature appears to be that diversification is generally achievable by adding real estate to a portfolio both in the short and long run, although these benefits may be weaker in indirect investments and during periods of economic and financial turmoil.

\section{Testing diversification loss}

\subsection{Estimating diversification loss: from the $R S R L$ to $m R S R L$}

Following Calvet et al. (2007), diversification losses can be proxied by comparing the Sharpe ratio of a given portfolio to the Sharpe ratio of a benchmark portfolio. Formally, we focus on the ex post Sharpe ratio, defined as follows:

Definition 1 (Sharpe, 1994). Let $\mu_{i}$ and $\sigma_{i}$ be the mean return and volatility of the portfolio $i$. Let $\mu_{j}$ and $\sigma_{j}$ be the mean return and volatility of the benchmark portfolio $j$. It is assumed that the benchmark portfolio is the risk-free rate, so $\mu_{j}=r_{f}$ and $\sigma_{j}=0$. It is assumed that these two moments are perfectly known and perfectly summarize the distribution of the portfolio return $i$. We note the Sharpe ratio $S_{i}$ as follows:

$$
S_{i}=\frac{\mu_{i}-r_{f}}{\sigma_{i}}
$$

For any portfolio $h$, we denote by $\mu_{h}$ and $\sigma_{h}$ the mean and standard deviation of the excess return on the risky portfolio and by $S_{h}$ the corresponding Sharpe ratio. Similarly, $S_{b}$ defines the Sharpe ratio of the benchmark portfolio. The loss from imperfect diversification with respect to the benchmark can be quantified by the relative Sharpe ratio loss. 
Definition 2 (Calvet et al., 2007). Let $S_{h}$ and $S_{b}$ be the Sharpe ratios of the portfolio $h$ and the benchmark portfolio b, respectively. The relative Sharpe ratio loss is as follows:

$$
R S R L_{h}=1-\frac{S_{h}}{S_{b}}
$$

As illustrated in Figure 1, the $R S R L$ relates the normalized difference of angles $\alpha_{h}-\alpha_{b}$. The $R S R L$ is defined on $[0,1]$; by construction, it equals zero for identical portfolios and one if the overall risk of portfolio $h$ is idiosyncratic only.

Figure 1: The $R S R L$ as a measure of underdiversification

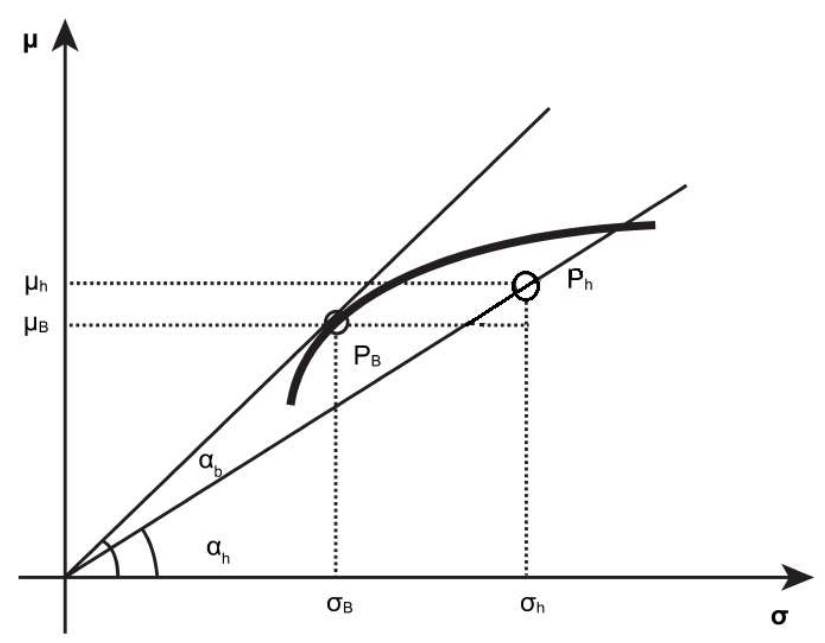

Notes: This figure illustrates the $R S R L$ roots in a mean-variance analysis. From this figure, trigonometry helps to understand the $R S R L$ as a measure of underdiversification.

Based on Sharpe ratios, this (under)diversification measure implicitly assumes that returns are fully characterized by their two first moments, i.e., the hypothesis of returns' normality. In case of a nonnormal distribution of asset returns (student - $t$, for example), the $R S R L$ depends on higher moments of the distribution (skewness, kurtosis, etc.). Therefore, the $R S R L$ no longer constitutes an indicator of diversification. In such a case, Ardia and Boudt (2015) recommended substituting the standard deviation with the modified Value-at-Risk and to build a modified Sharpe ratio $(m S)$ robust to higher moments. Several modified Sharpe 
ratios coexist in the literature. These ratios are based on different modified Value-at-Risk measures: Favre and Galeano (2002) and Gregoriou and Gueyie (2003) used a Cornish-Fisher (1937) expansion to calculate a modified VaR analytically. More recently, Bali et al. (2013) simply used the $V a R^{99 \%}$ to replace the standard deviation. Both approaches enable building a modified Sharpe ratio which is robust to nonnormal returns. We choose Gregoriou and Gueyie's modified Value-at-Risk (2003), as suggested in Ardia and Boudt (2015).

Definition 3 (Gregoriou and Gueyie, 2003). Let $\mu_{i}$ and $m V a R_{i}^{\alpha \%}$ be the mean return and the $1-\alpha \%$ Cornish-Fisher's approximation of the Value-at-Risk of the portfolio $i$ and $r_{f}$ the risk-free rate. We note the modified Sharpe ratio $g_{m}\left(\mu_{i}, m V a R_{i}^{\alpha \%}\right)=m S_{i}$ :

$$
m S_{i}=\frac{\mu_{i}-r_{f}}{m V a R_{i}^{\alpha \%}}
$$

The literature shows that the Cornish-Fisher approximation provides a more accurate estimation of the Value-at-Risk. This has been confirmed in a recent study; Amédée-Manesme et al. (2015) have also shown that, given the properties of commercial real estate indices, Value-at-Risk should be adjusted by a Cornish-Fisher approximation associated with a rearrangement procedure as in Chernozhukov, Fernández-Val and Galichon (2010) (essentially a simple reordering).

It is then possible to extend the $R S R L$, introducing the modified relative Sharpe ratio loss $(m R S R L)$ robust to nonnormally distributed returns:

Definition 4. Let $m S_{h}$ and $m S_{b}$ be the modified Sharpe ratios of the portfolio $h$ and the benchmark portfolio b, respectively. The modified relative Sharpe ratio loss is as follows:

$$
m R S R L_{h}=1-\frac{m S_{h}}{m S_{b}}
$$


Similarly to the $R S R L$, the $m R S R L$ is defined on $[0 ; 1]$ by construction ${ }^{1}$ and is a monotonic and decreasing function with respect to diversification.

Figure 2: The $R S R L$ and $m R S R L$ as measures of underdiversification
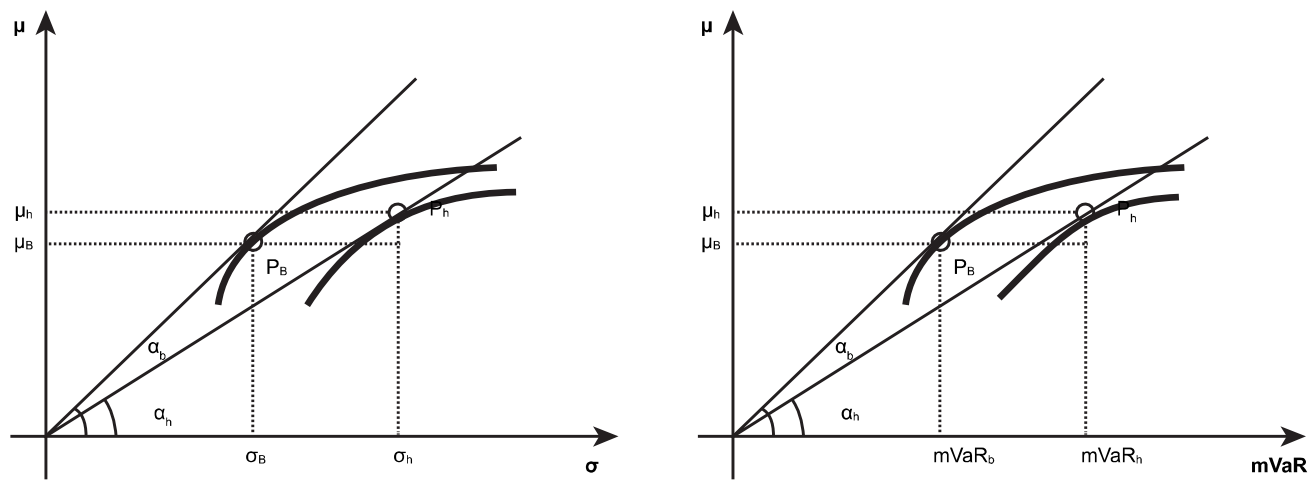

Notes: This figure illustrates the $R S R L$ (resp. $m R S R L$ ) rooted in a mean-variance (resp. mean- $m V a R$ ) analysis. From this figure, trigonometry helps to understand the $R S R L$ (resp. $m R S R L$ ) as a measure of underdiversification.

\subsection{Empirical counterparts for the RSRL and $m R S R L$}

In the previous section, it was assumed that the moments were exactly known and perfectly defined the distribution of the portfolio returns. We now consider the empirical counterpart (i.e., when the moments of the distribution are estimated). ${ }^{2}$ Under the assumption of normality of the portfolio returns' distribution, estimating the mean and variance is sufficient. Without loss of generality, the empirical counterpart of the $R S R L$ can then be expressed as:

$$
R S \hat{R} L_{h}=1-\frac{\hat{S_{h}}}{\hat{S}_{b}}
$$

where

$$
\hat{S}_{i}=\frac{\hat{\mu}_{i}-r_{f}}{\hat{\sigma}_{i}}, \quad i=(h, b),
$$

${ }^{1}$ It equals zero if the composition of portfolio $h\left(P_{h}\right)$ is identical to that of portfolio $b\left(P_{b}\right)$ but is lower than 1 , as we assume that the benchmark portfolio is the most diversified one.

${ }^{2}$ Estimated moments are indicated with a hat. 
$\hat{\mu}_{i}$ and $\hat{\sigma}_{i}$ being unbiased estimates of the mean and the variance of the portfolio returns.

Similarly, $m R \hat{S} R L_{h}=1-\frac{m \hat{S}_{h}}{m S_{b}}$, which requires an unbiased estimate of $m V a R_{i}^{\alpha \%}$.

To better understand the tests to be implemented in order to test for the diversification ability from the $R S R L$ and $m R S R L$, let us consider the two portfolios ( $b$ and $h$ ), with the following features:

$$
\mu=\left(\begin{array}{c}
\mu_{h} \\
\mu_{b}
\end{array}\right) \quad \text { and } \quad \Sigma=\left(\begin{array}{cc}
\sigma_{h}^{2} & \sigma_{h b} \\
\sigma_{h b} & \sigma_{b}^{2}
\end{array}\right) \text {, where } \mu \text { is the return and } \sigma \text { the risk. }
$$

A proper test to compare the diversification possibility of portfolio $h$ with respect to the benchmark $b$ would consist of testing for the nullity of the $R S R L$, i.e., $R S R L_{h}=1-\frac{S_{h}}{S_{b}}=0$. It is straightforward to notice that this null hypothesis is strictly equivalent to $\Delta=\mathrm{S}_{h}-\mathrm{S}_{b}=$ $\frac{\mu_{h}}{\sigma_{h}}-\frac{\mu_{b}}{\sigma_{b}}=0$. It is thus statistically strictly equivalent to test for the nullity of the $R S R L$ or the nullity of the Sharpe ratio difference $\Delta$. Hence, whether the null $\Delta=0$ is not rejected, portfolio $h$ does not offer diversification advantages, whereas it does under the alternative $\Delta \neq 0$.

Under normal iid returns, testing for diversification, and thus loss, boils down to:

$$
H_{0}: R S R L \equiv S_{b}-S_{h}=0
$$

Similarly, when higher moments are characterizing the returns' distribution, testing for diversification loss should be conducted at a particular risk level $(\alpha)$ using the modified Sharpe ratios at $\alpha$, denoted as $m R S R L(\alpha)$ (see Ardia and Boudt, 2015). We then focus on testing the significance of $m R S R L$ :

$$
H_{0}: m R S R L \equiv m S_{B}(\alpha)-m S_{h}(\alpha)=0
$$

Asymptotic distribution of both tests is relatively easy under these strong assumptions (see Memmel, 2003). However, considering "real world" financial data features as such strong assumptions (i.e., skewed distribution, autocorrelation, and heteroscedasticity to name but 
a few), such assumptions would likely be violated. Just as a practical example, the finite sample framework ( $<30$ observations per series) often encountered does not advocate in favor of asymptotic properties. In such a case, and following Ledoit and Wolf (2008) or Ardia and Boudt $(2015 ; 2018)$, a bootstrap version of the test appears as the solution. Both studies propose a studentized circular block version of the traditional bootstrap approach. Circular block-bootstrap has been proposed by Politis and Romano (1992). Contrary to conventional block-bootstrap methods, such as the moving block-bootstrap or the non-overlapping block-bootstrap, the circular block-bootstrap uses elements from the periodically extended series. Studentization consists in considering as the bootstraped test statistic $m R S R L^{b} / s\left(m R S R L^{b}\right)$, where ${ }^{b}$ indicates the $b$-th bootstrap draw and $s($.$) its standard er-$ ror instead of $m R S R L^{b}$. The studentized test statistic is asymptotically distributed as the absolute value of a standard normal random variable.

\section{Empirical analysis}

\subsection{Data}

Revisiting the diversification potential in real estate portfolios, we aim at investigating the relative size of both international and sectoral diversification benefits. Based on REITs data, most studies focus on either economic or geographical regions within several countries. Here, the objective is to compare diversification by country with diversification by property type. Our empirical contributions to the literature are to extend the empirical investigation to a panel of 16 OECD countries and 4 sectors (residential, retail, office and industrial) and to simultaneously consider the sectoral as well as the geographical dimensions of diversification.

Indeed, an international analysis of the diversification potential in the real estate market requires data returns at a disaggregated level for both the geographical and sectoral dimensions. Among the few data providers of international real estate returns, we therefore chose 
the MSCI (ex IPD) database. ${ }^{3}$ This database is the only one which fits our specifications, as it provides returns per country and per property type. However, because of missing values in the dataset, arbitrage between the number of countries and the number of observations (and data frequency) restricts the initial dataset. Descriptive statistics of the resulting database, covering real estate returns in 16 countries and 4 sectors from 1999 to 2018, are presented in Table 1.

Table 1: Real estate data returns - Descriptive statistics

\begin{tabular}{lcccccccc}
\hline \hline & AUS & CAN & DEN & FIN & FRA & GER & IRL & NLD \\
\hline Mean & 8.758 & 10.080 & 8.200 & 6.893 & 9.283 & 5.741 & 7.666 & 7.436 \\
Median & 9.575 & 9.850 & 8.200 & 6.250 & 8.900 & 5.325 & 9.250 & 8.100 \\
Std Error & 4.109 & 4.435 & 4.880 & 1.999 & 5.712 & 2.843 & 14.513 & 4.623 \\
Kurtosis & 2.157 & 0.885 & 2.266 & 1.587 & 0.723 & -0.324 & 0.768 & -1.101 \\
Skewness & -1.323 & -0.511 & 1.429 & 1.415 & 0.150 & 0.577 & -0.974 & -0.298 \\
Country level & Yes & Yes & Yes & Yes & Yes & Yes & Yes & Yes \\
Sector level & Yes & Yes & Yes & Yes & Yes & Yes & Yes & Yes \\
\hline \hline & NZL & NOR & POR & SAF & SPA & SWE & UK & USA \\
\hline Mean & 10.009 & 10.078 & 5.788 & 13.842 & 6.947 & 9.705 & 9.497 & 8.912 \\
Median & 9.875 & 10.425 & 6.575 & 10.825 & 8.850 & 9.900 & 10.425 & 11.775 \\
Std Error & 5.258 & 5.809 & 3.165 & 6.477 & 7.662 & 5.222 & 8.612 & 8.496 \\
Kurtosis & -0.156 & 2.493 & -0.456 & 0.056 & -0.372 & 0.814 & 7.086 & 6.250 \\
Skewness & -0.383 & -0.262 & -0.410 & 1.140 & -0.481 & -0.026 & -2.234 & -2.377 \\
Country level & Yes & Yes & Yes & Yes & Yes & Yes & Yes & Yes \\
Sector level & Yes & Yes & Yes & Yes & Yes & Yes & Yes & Yes \\
\hline \hline
\end{tabular}

Notes: This table reports descriptive statistics of real estate data returns. The initial dataset, covering 16 countries and 4 sectors over a period from 1999 to 2018, is extracted from the MSCI Property Indexes (ex IPD) database.

\subsection{Diversification potential in real estate portfolios}

In this section, we aim at investigating the diversification potential of direct real estate markets. Using the MSCI Property Indexes (ex IPD) database, we first build a set of three real estate portfolios from country-level, property-level and global indices, respectively.

\footnotetext{
${ }^{3}$ Documentation about IPD Property Fund Indexes can be found here: https://www.msci.com/ real-estate-indexes.
} 
Specifically, we use two optimization frameworks: the Markowitz and Black-Litterman models. As a first step in our analysis, we compute efficient frontiers in both cases. Mean-variance graphs are plotted in Figure 2.

Figure 3: Comparing diversification potential
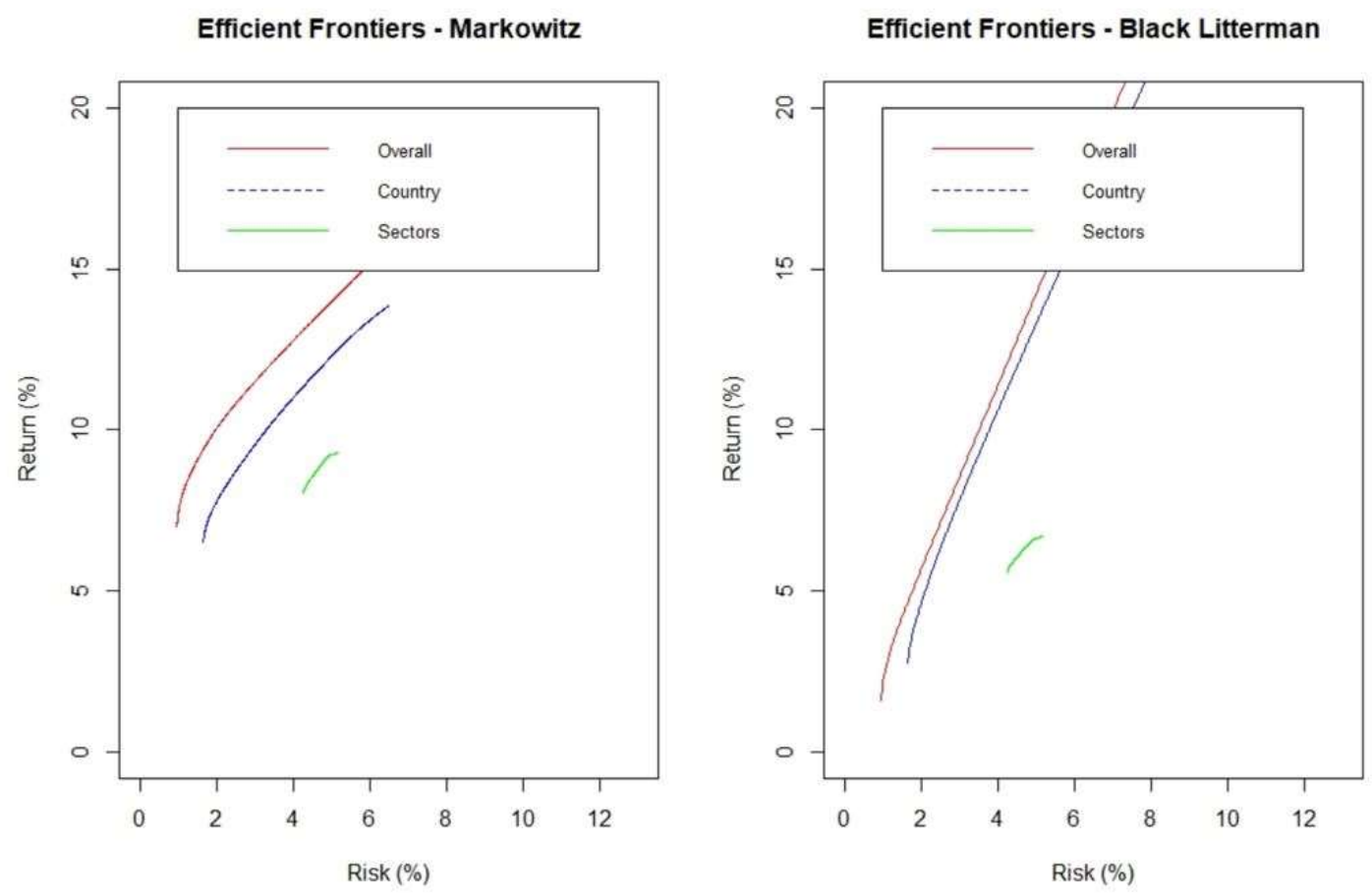

Notes: This figure illustrates Markowitz and Black-Litterman mean - variance analysis. This figure enables the comparison of the diversification potential from the measured differences between the benchmark portfolio and the two subportfolios with respect to investing at country- and sector-level, respectively.

Results illustrated in Figure 1 indicate that investing in country- or sector-levels indices only reduces diversification possibilities. Indeed, with the Overall efficient frontier being the benchmark portfolio, the distance between this efficient frontier and the two others is related to diversification loss. Furthermore, we observe that the Country efficient frontiers lie closer to the Overall efficient frontier than to the Sectors efficient frontier. Thus, investing in countrylevel indices only appears to be more efficient than investing in sector-level indices alone. In both the Markowitz and Black-Litterman frameworks, mean-variance analysis exhibits similar features. Country-level diversification dominates sector-level diversification in both cases. Furthermore, in the Black-Litterman framework, the results appear to be amplified. 
Compared with the Overall efficient frontier, we observe that investing in country-level indices only induces a slight diversification loss, whereas investing in sector-level indices induces a greater one.

In a second step, we analyze the diversification loss induced by restricting the set of opportunity. Extending the $R S R L$ proposed by Calvet et al. (2007) and the $m R S R L$, its modified version (in its studentized and not studentized version), we can test for the significance of the diversification loss. Using analytical results from Section 3, we compute estimates and associated significance levels in both the Markowitz and Black-Litterman frameworks. Studentized and percentile circular block-bootstrap exhibit the same results about significance levels. The results are reported in Table 2 .

Table 2: Estimating diversification loss

\begin{tabular}{l|c|c|c}
\hline \hline & Framework & Countries & Sectors \\
\hline Test & Markowitz & $0.45^{* *}$ & $0.74^{* * *}$ \\
$R S R L$ & Black-Litterman & 0.39 & $0.19^{* * *}$ \\
\hline Test & Markowitz & $0.14^{*}$ & $0.28^{* *}$ \\
$m R S R L$ & Black-Litterman & 0.05 & $0.09^{* *}$ \\
\hline \hline
\end{tabular}

Notes: This table enables the comparison of the diversification potential from the $R S R L$ (resp. $m R S R L$ ) differences between the benchmark portfolio and the two subportfolios with respect to investing at country- and sector-level, respectively. Significance levels of the RSRL (resp. $m R S R L$ ) coefficient are computed via a studentized circular block-bootstrap as in Ardia and Boudt (2015). Results are computed using $\mathrm{R}$ 3.6.0 ( $\mathrm{R}$ Core Team, 2020) and DiversificationR (v0.1.0; Hasse, 2021) package. The full reproducible code is available on CRAN. Labels $* * *, * *$ and $*$ indicate significance at $99 \%, 95 \%$ and $90 \%$ levels, respectively.

It first turns out that the studentized and the non-studentized circular block-bootstrap diversification test lead to the same outcomes. In both the Markowitz and Black-Litterman frameworks, the results indicate that the diversification loss is stronger for sector-level diversification than for country-level diversification. Indeed, the $R S R L$ (resp. $m R S R L$ ) estimates for sector-level portfolios are twice greater than the one for country-level portfolios. However, significance levels differ in the Markowitz and Black-Litterman cases. The diversification loss is highly significant in every case, except at the country-level for the Black-Litterman framework. These results are in line with our findings illustrated in Figure 1. In the two risk-return graphs, the distance between Overall and Country efficient frontiers is smaller 
than that between Overall and Sectors. Moreover, this feature is the most pronounced in the Black-Litterman case, in which the distance loss induced by investing at country-level without diversifying by property type turns out to be negligible. Estimating both coefficient and significance level of the $R S R L$ and $m R S R L$ statistics constitutes an intuitive and relevant way to measure diversification of a given portfolio relative to a benchmark portfolio.

In a third step, we empirically validate the relevance of our extensions of the $R S R L$. To do so, we compare the empirical results with those obtained considering the other diversification measures. Specifically, we focus on the four most recent diversification measures found in the literature. These measures are listed in Table 3.

Table 3: Diversification potential - Diversification measures

\begin{tabular}{l|c|c}
\hline \hline Name & ID & References \\
\hline Portfolio Diversification Index & $P D I$ & Rudin and Morgan (2006) \\
Diversification Ratio & $D R$ & Choueifaty and Coignard (2008) \\
Diversification Delta & $D D$ & Vermorken et al. (2012) \\
Diversification Delta Star & $D D^{*}$ & Flores et al. (2017) \\
Relative Sharpe Ratio Loss & $R S R L$ & Calvet et al. (2007) \\
\hline \hline
\end{tabular}

Notes: This table reports a set of the five main diversification measures from the recent literature.

Contrary to early diversification measures (e.g., Herfindahl - Hirschman Index and Shannon entropy), recent measures described in Table 3 take both weights and covariance into account. Our set of diversification measures aims at achieving a fair comparison between those, as well as the new ones $(R S R L / m R S R L)$. The outcomes of the formal diversification tests are reported in Tables 4 (Markowitz framework) and 5 (Black-Litterman framework).

The results indicate that diversification measures are statistically higher at a country-level than at a sector-level. The only exception is the PDI scores, for which the country-level and sectoral-level diversification are roughly similar. Such a finding derives its justification from the definition of the PDI scores. They are built from the eigenvalues of the covariance matrix of the portfolio via a principal component analysis. However, if these diversification measures are relevant to quantify the level of diversification of a given portfolio, they only constitute some absolute measures of diversification. In other words, these diversification measures 
Table 4: Diversification potential - Markowitz framework

\begin{tabular}{l|c|c|c}
\hline \hline & Countries \& Sectors & Countries & Sectors \\
\hline Portfolio Diversification Index $(P D I)$ & 2.669 & 1.762 & 1.790 \\
Diversification Ratio $(D R)$ & 2.729 & 1.504 & 1.017 \\
Diversification Delta $(D D)$ & 0.585 & 0.291 & 0.014 \\
Diversification Delta Star $\left(D D^{*}\right)$ & 0.634 & 0.335 & 0.017 \\
Relative Sharpe Ratio Loss $(R S R L)$ & & $0.45^{* *}$ & $0.74^{* * *}$ \\
Modified Relative Sharpe Ratio Loss $(m R S R L)$ & & $0.14^{*}$ & $0.28^{* *}$ \\
\hline \hline
\end{tabular}

Notes: This table reports the estimation results of six different diversification measures on Markowitz mean - variance optimal portfolios. This table enables the comparison of the diversification potential from the measured differences between the benchmark portfolio and the two subportfolios with respect to investing at country- and sector-level, respectively. Significance levels of the $R S R L$ (resp. mRSRL) coefficient ar computed via a studentized circular block-bootstrap as in Ardia and Boudt (2015). Results are computed using R 3.6.0 (R Core Team, 2020) and the Diversification $(v 0.1 .0$; Hasse, 2021) package. The full reproducible code is available on CRAN. Labels $* * *, * *$ and $*$ indicate significance at $99 \%, 95 \%$ and $90 \%$ levels, respectively.

Table 5: Diversification potential - Black-Litterman framework

\begin{tabular}{l|c|c|c}
\hline \hline & Countries \& Sectors & Countries & Sectors \\
\hline Portfolio Diversification Index $(P D I)$ & 2.669 & 1.762 & 1.790 \\
Diversification Ratio $(D R)$ & 1.558 & 1.155 & 1.036 \\
Diversification Delta $(D D)$ & 0.246 & 0.075 & 0.032 \\
Diversification Delta Star $\left(D D^{*}\right)$ & 0.358 & 0.134 & 0.035 \\
Relative Sharpe Ratio Loss $(R S R L)$ & & 0.39 & $0.19^{* * *}$ \\
Modified Relative Sharpe Ratio Loss $(m R S R L)$ & & 0.05 & $0.09^{* *}$ \\
\hline \hline
\end{tabular}

Notes: This table reports the estimation results of six different diversification measures on Black-Litterman mean - variance optimal portfolios. This table enables the comparison of the diversification potential from the measured differences between the benchmark portfolio and the two subportfolios with respect to investing at country- and sector-level, respectively. Significance levels of the $R S R L$ (resp. mRSRL) coefficient are computed via a studentized circular block-bootstrap as in Ardia and Boudt (2015). Results are computed using R 3.6.0 (R Core Team, 2020) and the Diversification $(v 0.1 .0$; Hasse, 2021) package. The full reproducible code is available on CRAN. Labels $* * *, * *$ and $*$ indicate significance at
$99 \%, 95 \%$ and $90 \%$ levels, respectively. 
are designed to provide an absolute score from given portfolio weights and covariance. Thus, comparing absolute and relative diversification scores computed from several efficient frontiers (i.e., comparing diversification benefits across subsets of investment opportunities) leads to interpretation biases.

To summarize, we empirically validate the relevance of our diversification test based on the $R S R L$ (resp. $m R S R L$ ) estimates and confidence intervals. Indeed, the $R S R L$ is an intuitive statistical measure offering several advantages compared to other diversification measures. First, the $R S R L$ (resp. $m R S R L$ ) is a relative measure of diversification loss, based on the efficiency loss between a given portfolio and its benchmark portfolio. This efficiency loss is intuitively related to the distance between the optimal portfolios located on the tangent of the two efficient frontiers. Thus, the $R S R L$ is designed as a statistical measure allowing comparison of diversification abilities of several portfolios. Last but not least, finite and asymptotic inference for the $R S R L$ (resp. $m R S R L$ ) is precisely known, which is not the case for the other diversification measures. It is therefore possible to set up a test for diversification loss from these diversification measures.

\section{Conclusions}

The diversification potential of real estate is well acknowledged among scholars and practitioners. However, whether diversification can be best achieved on a global scale by diversifying portfolios across property types or geographic markets in different countries is still not well understood. Our study addresses this issue, revisiting the diversification potential in real estate portfolios and developing a new diversification test.

Several diversification measures coexist in the literature. Most of these are easy to compute but are only descriptive, weakly connected to the economic background and lack information on confidence intervals. Considering these drawbacks, we follow Calvet et al. (2007)'s approach based on the measure of financial loss from holding a subefficient portfolio. Specifically, we extend their diversification measure by building a diversification test that allows 
for inference asymptotically but also in finite non-iid residuals. Based on Ardia and Boudt (2015)'s test for equality of modified Sharpe ratios, we first compute robust confidence intervals for the estimator $R \hat{S R L}$ via a studentized circular block bootstrap procedure. Then, we introduce a modified version of Calvet et al. (2007)'s $R S R L$, the $m R S R L$, to have an estimator that is robust to nonnormality.

Focusing on direct real estate, we use the MSCI (ex IPD) database to build a unique dataset of real estate market returns covering 16 OECD countries over the period 1999-2018. The resulting balanced panel dataset includes the returns for each country but also considers different property types (residential, retail, office and industrial), enabling a precise evaluation of the diversification potential of real estate portfolios. Comparing the efficient frontiers of each strategy in both the Markowitz and Black-Litterman frameworks, the preliminary results indicate that the diversification loss is stronger at the sectoral level than it is at the country level. Diversification loss is significant in every case, except at the country level for the BlackLitterman framework. Then, using five different diversification measures from the literature, we investigate the diversification potential of real estate portfolios. Our empirical findings broadly reveal that international diversification strategies outperform sectoral diversification strategies in terms of real estate assets. Our results have several implications for practitioners. First, allowing for a robust estimation of the $R S R L$ and $m R S R L$ statistics constitutes an intuitive and relevant way to measure the diversification of a given portfolio relative to a benchmark portfolio. Second, in line with Heston and Rouwenhorst's (1994) early results, our empirical findings reveal that international diversification strategies outperform sectoral diversification strategies in a real estate context.

Finally, the econometric approach proposed in this paper may be applied in future research to other asset classes suffering from similar data and statistical constraints, such as private equity, cryptocurrency or hedge funds. Our diversification test can also be used by practitioners, investors and financial advisors to investigate the diversification level of mutual funds by comparing them to their benchmark. 


\section{References}

Amédée-Manesme, C. O., Barthélémy, F., \& Keenan, D. (2015). Cornish-Fisher expansion for commercial real estate value at risk. The Journal of Real Estate Finance and Economics, 50(4), 439-464.

Ardia, D., \& Boudt, K. (2015). Testing equality of modified Sharpe ratios. Finance Research Letters, 13, 97-104.

Ardia, D., \& Boudt, K. (2018). The peer performance ratios of hedge funds. Journal of Banking E Finance, 87, 351-368.

Artzner, P., Delbaen, F., Eber, J. M., \& Heath, D. (1999). Coherent measures of risk. Mathematical Finance, 9(3), 203-228.

Bali, T. G., Brown, S. J., \& Demirtas, K. O. (2013). Do hedge funds outperform stocks and bonds?. Management Science, 59(8), 1887-1903.

Byrne, P., \& Lee, S. (2003). An exploration of the relationship between size, diversification and risk in UK real estate portfolios: 1989-1999. Journal of Property Research, 20(2), 191206.

Calvet, L. E., Campbell, J. Y., \& Sodini, P. (2007). Down or out: Assessing the welfare costs of household investment mistakes. Journal of Political Economy, 115(5), 707-747.

Calvet, L. E., Campbell, J. Y., \& Sodini, P. (2009). Measuring the financial sophistication of households. American Economic Review, 99(2), 393-98. 
Chatrath, A., Liang, Y., \& McIntosh, W. (2000). The asymmetric REIT-beta puzzle. Journal of Real Estate Portfolio Management, 6(2), 101-111.

Chernozhukov, V., Fernández-Val, I., \& Galichon, A. (2010). Rearranging EdgeworthCornish-Fisher expansions. Economic Theory, 42(2), 419-435.

Chiang, K., Lee, M. L., \& Wisen, C. (2004). Another look at the asymmetric REIT-beta puzzle. Journal of Real Estate Research, 26(1), 25-42.

Choueifaty, Y., \& Coignard, Y. (2008). Toward maximum diversification. The Journal of Portfolio Management, 35(1), 40-51.

Choueifaty, Y., Froidure, T., \& Reynier, J. (2013). Properties of the most diversified portfolio. Journal of Investment Strategies, 2(2), 49-70.

Clayton, J., \& MacKinnon, G. (2001). The time-varying nature of the link between REIT, real estate and financial asset returns. Journal of Real Estate Portfolio Management, 7(1), 43-54.

Dimmock, S. G., Kouwenberg, R., Mitchell, O. S., \& Peijnenburg, K. (2018). Household portfolio underdiversification and probability weighting: Evidence from the field (No. w24928). National Bureau of Economic Research.

Eichholtz, P. M., Hoesli, M., MacGregor, B. D., \& Nanthakumaran, N. (1995). Real estate portfolio diversification by property type and region. Journal of Property Finance, 6(3), 3959. 
Favre, L., \& Galeano, J. A. (2002). Mean-modified Value-at-Risk optimization with hedge funds. The Journal of Alternative Investments, 5(2), 21-25.

Feng, Z., Pattanapanchai, M., Price, S. M., \& Sirmans, C. F. (2019). Geographic diversification in real estate investment trusts. Real Estate Economics, 1-20.

Flores, Y. S., Bianchi, R. J., Drew, M. E., \& Trück, S. (2017). The diversification delta: A different perspective. The Journal of Portfolio Management, 43(4), 112-124.

Goldstein, M., \& Nelling, E. (1999). REIT Return Behavior in Advancing and Declining Stock Markets. Real Estate Finance, 15(4), 68-77.

Gregoriou, G. N., \& Gueyie, J. P. (2003). Risk-adjusted performance of funds of hedge funds using a modified Sharpe ratio. The Journal of Wealth Management, 6(3), 77-83.

Hartzell, J. C., Sun, L., \& Titman, S. (2014). Institutional investors as monitors of corporate diversification decisions: Evidence from real estate investment trusts. Journal of Corporate Finance, 25, 61-72.

Hasse, Jean-Baptiste. (2021) "DiversificationR: Econometric Tools to Measure Portfolio Diversification". R package version 0.1.0. https://CRAN.R-project.org/package=DiversificationR

Heaney, R., \& Sriananthakumar, S. (2012). Time-varying correlation between stock market returns and real estate returns. Journal of Empirical Finance, 19(4), 583-594.

Heston, S. L., \& Rouwenhorst, K. G. (1994). Does industrial structure explain the benefits of international diversification?. Journal of Financial Economics, 36(1), 3-27. 
Hoesli, M., \& Reka, K. (2015). Contagion channels between real estate and financial markets. Real Estate Economics, 43(1), 101-138.

Hoesli, M., \& Reka, K. (2013). Volatility spillovers, comovements and contagion in securitized real estate markets. The Journal of Real Estate Finance and Economic, 47(1), 1-35.

Hoesli, M., \& Oikarinen, E. (2012). Are REITs real estate? Evidence from international sector level data. Journal of International Money and Finance, 31(7), 1823-1850.

Hoesli, M., Lizieri, C., \& MacGregor, B. (2008). The inflation hedging characteristics of US and UK investments: a multi-factor error correction approach. The Journal of Real Estate Finance and Economics, 36(2), 183-206.

Ledoit, O., \& Wolf, M. (2008). Robust performance hypothesis testing with the Sharpe ratio. Journal of Empirical Finance, 15(5), 850-859.

Leone, V., \& Ravishankar, G. (2018). Frontiers of commercial real estate portfolio performance: Are sector-region-efficient diversification strategies a myth or reality?. Journal of Property Research, 35(2), 95-116.

Lizieri, C. (2013). After the fall: real estate in the mixed-asset portfolio in the aftermath of the global financial crisis. The Journal of Portfolio Management, 39(5), 43-59.

MacKinnon, G. H., \& Al Zaman, A. (2009). Real estate for the long term: the effect of return predictability on long-horizon allocations. Real Estate Economics, 37(1), 117-153. 
Markowitz, H. (1952). Portfolio selection. The Journal of Finance, 7(1), 77-91.

Memmel, C. (2003). Performance hypothesis testing with the Sharpe ratio. Finance Letters, $1(1)$

Meucci, A. (2009). Managing Diversification. Risk, 22(5), 74-79.

Peterson, J. D., \& Hsieh, C. H. (1997). Do common risk factors in the returns on stocks and bonds explain returns on REITs?. Real Estate Economics, 25(2), 321-345.

Politis, D. N., \& Romano, J. P. (1992). A circular block-resampling procedure for stationary data. Exploring the limits of bootstrap, 2635270.

R Core Team. "R: A language and environment for statistical computing." R Foundation for Statistical Computing, Vienna, Austria. (2020) https://www.R-project.org/.

Rehring, C. (2012). Real estate in a mixed-asset portfolio: The role of the investment horizon. Real Estate Economics, 40(1), 65-95.

Roche, H., Tompaidis, S., \& Yang, C. (2013). Why does junior put all his eggs in one basket? A potential rational explanation for holding concentrated portfolios. Journal of Financial Economics, 109(3), 775-796.

Rudin, A. M., \& Morgan, JS. (2006). A portfolio diversification index. The Journal of Portfolio Management, 32(2), 81-89.

Serrano, C., \& Hoesli, M. (2010). Are securitized real estate returns more predictable than 
stock returns?. The Journal of Real Estate Finance and Economics, 41(2), 170-192.

Sharpe, W. F. (1994). The Sharpe ratio. The Journal of Portfolio Management, 21(1), 49-58.

Simon, S., \& Ng, W. L. (2009). The effect of the real estate downturn on the link between REITs and the stock market. Journal of Real Estate Portfolio Management, 15(3), 211-219.

Sing, T. F., \& Tan, Z. Y. (2013). Time-varying correlations between stock and direct real estate returns. Journal of Property Investment 83 Finance, 31(2), 179-195.

Solnik, B. H. (1974). An equilibrium model of the international capital market. Journal of Economic Theory, 8(4), 500-524.

Statman, M., \& Scheid, J. (2008). Correlation, return gaps, and the benefits of diversification. The Journal of Portfolio Management, 34(3), 132-139.

Tang, N., Mitchell, O. S., Mottola, G. R., \& Utkus, S. P. (2010). The efficiency of sponsor and participant portfolio choices in 401 (k) plans. Journal of Public Economics, 94(11-12), 1073-1085.

Tasche, D. (2006). Measuring sectoral diversification in an asymptotic multi-factor framework. Journal of Credit Risk, 2(3), 33-55.

Teuben, B., \& Neshat, R. (2020). Real Estate Market Size. Annual Update on the Size of the Professionally Managed Global Real Estate Investment Market. MSCI report, June 2020.

Vermorken, M. A., Medda, F. R., \& Schröder, T. (2012). The diversification delta: A higher- 
moment measure for portfolio diversification. The Journal of Portfolio Management, 39(1), $67-74$.

Von Gaudecker, H. M. (2015). How does household portfolio diversification vary with financial literacy and financial advice? The Journal of Finance, 489-507.

Worzala, E., \& Newell, G. (1997). International real estate: A review of strategic investment issues. Journal of Real Estate Portfolio Management, 3(2), 87-96. 